\title{
Optimization of Source-Wire-Gas Systems for Efficient Robot Welding
}

\author{
Zdenek Hudec ${ }^{1}$ \\ ${ }^{1}$ Technical University of Liberec, KSP, Studentska 2, 46117 Liberec, Czech republic
}

Received 15 April 2010, Accepted 20 June 2010

\begin{abstract}
GMAW (Gas-Metal-Arc-Welding) as the last of main technologies, yet based for a most part on manual (semiautomatic) work, is gradually automated. But traditional advances of weld design, technology and quality assurance is not essentially changing. The result is non-efficient welding (overwelding). Especially T-joint (fillet weld), that is the most employed type of joint in welded structures, due to its geometry is often overwelded and twice or 3 times as much volume must be filled with metal as is needed for desired size. That increases not only direct costs and weight but also the shrinkage force and distortion that cause other added costs. This paper presents a new access to Design and Process optimization of T-joint and V-grooved Welding, based on fillet and butt weld performance efficiency optimizing of given source-wiregas system with the help of set of experiments performance, proposed with DOE statistical method of central composite design. Moreover a new parametric field of stable metal transfer was discovered that markedly improves penetration and therefore performance efficiency.
\end{abstract}

Key words: GMAW, Fillet weld, T-joint, V-grooved joint, Optimization, Weld performance efficiency

\section{Introduction}

GMAW, used for joining of structural components, is widely employed as one of major fabrication process in industry and mostly plays a crucial role in determining the cost and quality of finished products and structures. Due to accompanying negative factors - stress and distortion, heat affected zone of base material, hydrogen absorption and defects emergence - using of welding technology is based on a very complex system of quality assurance. Design of weldments and welded structures has its own original multidisciplinary "production convenient" access, demonstrated on fig. 1.

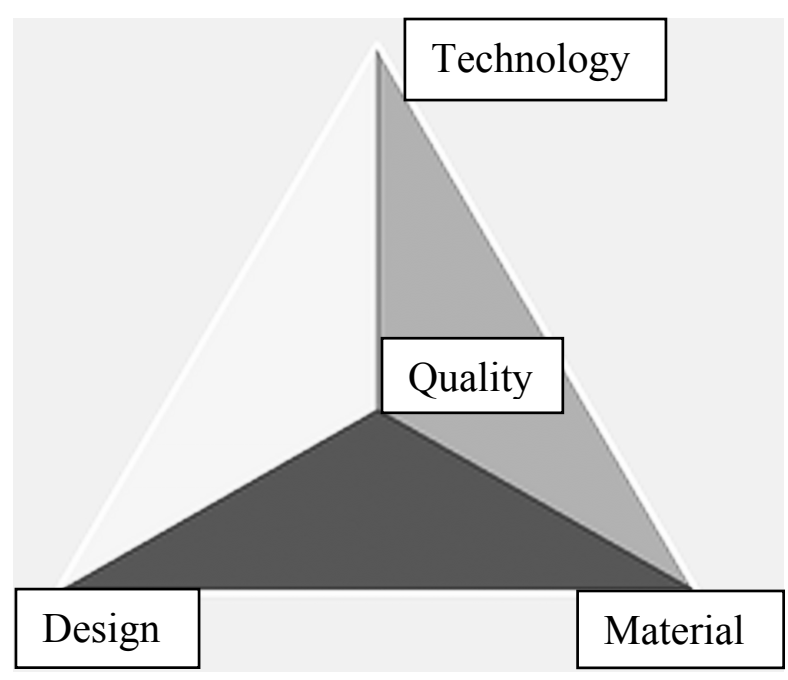

Fig. 1. Schema of welded structures design

Design must serve the purpose of structures, welded with chosen technology and material is chosen according to mechanical properties required in design, but the main factor of the whole design process there is join's property, connected with weldability that has changed from former material's factor to complex factor of quality assurance, defined (ISO) as keeping integrity of a material, manufactured with welding technology and preservation of joint properties, conform to design.

Quality assurance plays a crucial role in this system and due to fact, that quality of finished weldment cannot be evaluated by means of NDT control, another means of attests and various documents are used. Development from bureaucracy and paperwork to f.f.p. or f.f.s. (fitness for purpose or service) access is the main direction to welding productivity and efficiency increasing.

This access includes lightweight structures design with minimal share of additive weld metal that means assembled with minimum parts of minimal material's thickness and of course, as the base of it, joined with minimal number and volume of welds that is the object of this work. The following are GMAW "for and against" in this process.

\subsection{General rule vs. overwelding and fit-up conditions}

Even though all bead shapes are usable for various joint geometry and fit-up conditions in GMAW of structures and weldments, general rule of effective welding specifies that for stress-strain and metallurgical reasons in welding there is preferable to melt the minimum amount of material and melt the material with the minimum input energy because the energy, especially spent for melting of the consumable material significantly contributes to excessive welding costs and especially increases the shrinkage stress that affects distortion. Welded structure often includes many noise factors, such as poor fit-up. That makes difficult process automation. This is the reason why great portion of welding practice is still performed manually and therefore is based on welder skills that causes overwelding problem, especially for fillet welds (overwelding = laying down more weld metal than is structurally required). 


\subsection{GMAW metal transfer stability and melting rate}

Replacing flux with shielding gas and GMAW (gas-metalarc-welding) method developing has brought spatial freedom of arc that enabled robot application of arc, but at the costs of some process restriction. Process GMAW was the last of arc processes that was introduced to praxis. At 70 -th, due to strong surface tension in low-current process stability field, only sources with improved dynamic condition and using thin wire, special short-arc metal transfer enabled welding with allowable spatter. Even now, welding pool dynamic behaviour during metal transfer causes that only several modes of metal transfer are useable inside of determined process variables fields. These fields vary each other with process intensity (power density), efficiency, productivity, certain material application and especially vary with sourcewire-gas system used. Regarding to boundless development of GMAW method during last 40 years a lot of new sourcewire-gas systems emerged and are performed for countless practical applications. Source with flat U-I characteristic with high speed feeding of thin wire and low penetrated short-arc process predicted this process for deposited (filled) welding. After first period, when only productivity and costs were concerned, special systems for special purposes begun to be developing during 90-th, when new inverter sources were developed. These sources opened new fields of stable metal transfer, especially non-spatter controlled droplet pulsed arc and two high productive processes - rapid short-arc and rotated arc. Both were high deposited but low penetrated. Revolutionary source improving was accompanied with 2 and 3 (or even 4) gases mixture shielding. Never-the-less this trend enabled only increasing of weld deposition rate $=$ high productivity of bevel and gap filling that is not the same as welding.

Similar effect was reached with another way - using flux and metal cored wires with higher melting rates and better transfer stability than solid wires. All these methods of rapid filling the joint bevel with weld deposition suits well especially for manual (semiautomatic) welding and for variable and poor fit-up condition.

\subsection{Manual and automatic manner of welding}

Welder`s skills for filling any gap or bevel in any position with specified weld shape and size - that is the base of long and hard training in welding school. It is based on proper weaving of torch during slow forward movement. Some illustrated textbooks describe very closely this manner - Jeffus at al. [1], shown on fig. 3 and fig. 26. Current and therefore melting rate has to be low because of wire feed control assurance and than a penetration is shallow. On the contrary, automatic welding is mostly based on string bead with high travel speed and high current and therefore deep penetration.

The rate of automation in welding is increasing. Improved fit-up conditions due to precise details preparation and more accurate assembly, accompanied with CNC robot driving and laser sensing, supported with proper software, emulates real vision; all these factors together give the right conditions for replacing of manual welding methods with automation, costs reduction and productivity increasing.

\subsection{GMAW power density, common criteria of process efficiency, conduction vs. convection}

As mentioned above, due to base conception of GMAW, weld penetration depends on the net energy input, especially on the amperage value, so as the melting rate of the wire, therefore melting of the base metal and penetration is limited. Never-the-less due to complex action of various physical forces in heat and metal transfer and liquid flow in the weld pool, the resulted interval of dilution ranges from 30 to $60 \%$ and the bead geometry varies in penetration from wide shallow to the narrow and deep finger-tip shape, very close to key-hole action.

\section{Criteria used:}

Dilution of weld metal with base metal $\boldsymbol{D}$ (1) is commonly used gauge for GMAW power density effect evaluation.

$$
\boldsymbol{D}=\left(P_{S}-P_{N}\right) / P_{S} \cdot 100[\%],
$$

where $\boldsymbol{P}_{\boldsymbol{S}}$ is weld bead etched cross-section area and $\boldsymbol{P}_{\boldsymbol{N}}$ is deposited part of this area.

This purely geometrical criterion, even though it is accompanied with a current, has no connection with process variables and quality.

Melting efficiency $\eta_{\boldsymbol{m}}$ (2) is derived from the primary function performed by fusion welding heat sources that is to melt metal. The term efficiency denotes the fraction of the net energy input that actually melts base metal. Whereas the heat transfers (arc) efficiency is purely a heat source and used gas characteristic, the melting efficiency is a characteristic of both the heat source, gas and the process of heat transfer in the materials being joined. The melting efficiency under a given condition can be determined from post-weld knowledge of the cross-section area of the weld, the material welded, and the net energy input $\boldsymbol{Q}_{1}(3)$,

$$
\begin{array}{r}
\eta_{m}=\frac{Q \cdot\left(P_{S}-P_{N}\right)}{Q_{1}}, \\
Q_{1}=0,06 \cdot \eta_{a} \cdot \frac{U \cdot I}{v_{S}}[\mathrm{~kJ} / \mathrm{cm}],
\end{array}
$$

where $\boldsymbol{\eta}_{\mathbf{a}}$ is arc efficiency, $\mathbf{Q}$ is melting enthalpy, $\mathbf{I}(\mathrm{A})$ is amperage, $\mathbf{v}_{\mathbf{S}}(\mathrm{m} / \mathrm{min})$ is travel speed and $\mathbf{U}(\mathrm{V})$ is voltage. This power density indicator has close connection with process variables that is apparent in study of DuPont and Marder [2] where there was shown that travel speed governs the melting efficiency of all arc processes. Strong dependence was especially obtained in melting efficiency as a function of synergic effect of arc power and travel speed. Measured range of melting efficiency for various metal transfer conditions in our experiments was observed between 0.1 and 0.35 . Nevertheless this factor is based on the model of radial conduction heat transfer $\left(\alpha / \mathrm{v}_{\mathrm{s}}\right.$ factor) and also has no connection with process quality.

GMAW experimental studies and numerical modeling of heat transfer in weld pool during last ten years established that dominate mode of heat transfer during power density GMAW in the steel weld pool there is convection and the effect of various driving forces on liquid metal convection is highly complicated - as Wells [3] discussed. Advanced computational technique on the present enable creating more and 
more realistic model of heat and fluid flow during GMAW but the most realistic and easier access there is an experimental study.

\section{New strategy for weld design and performance}

Replacing manual welding with automation requires first of all changing common practice in design, performance, measuring and inspection of especially fillet welds.

\subsection{Fillet weld design and performance optimiza- tion}

\subsubsection{Present state of design and performance for manual manner fillet welding}

Fillet weld, especially in T-joint, is the most employed type of joint in welded structures. On the contrary of butt joint, the size of fillet is not limited with the thickness of material (except of lap joint on fig. 3) and therefore it inclines more to overwelding problems. It's ideal "filled" (fillet-deposited) cross-section area is throat size squared $\mathrm{a}^{2}$ and every millimeter over its calculated size contributes with a great deal to area growing and in the same way to growing of costs and general shrinking force (fig. 2a). Common problem FilletDeposited Overwelding is simply a rate of measured (deposited) and ideal designed size squared.

Weld bead, created usually in PB position, slowly with torch weaving, directed $45^{\circ}$ to the centre of the horizontal plate, is non-regular and has low penetration.

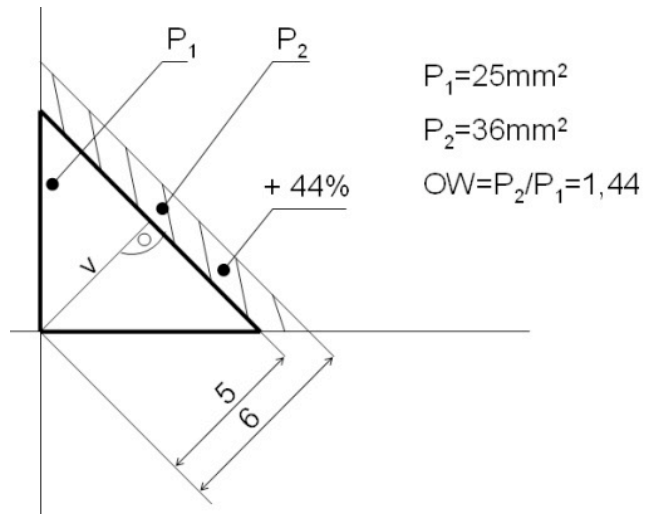

Fig. 2a. Fillet-deposited weld

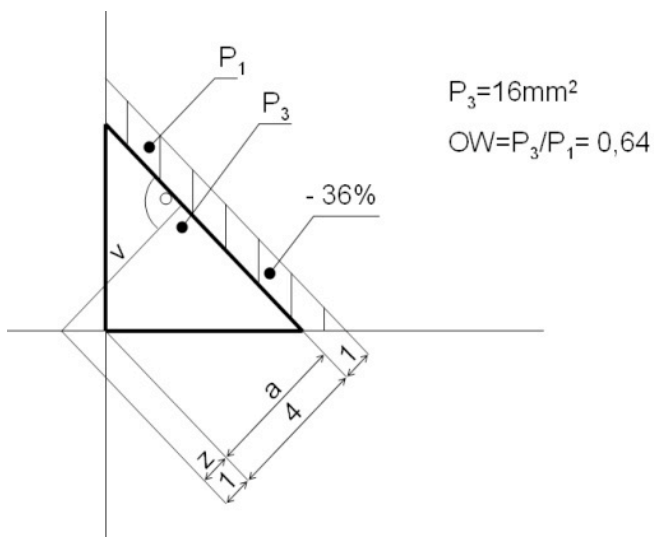

Fig. 2b. Fillet-penetrated weld
On the other hand, required deposited area dramatically decreases, when automatic welding in PA (ev. PG) position is used and penetration could be counted in computing the weld throat thickness $\mathbf{v}$ (fig. 2b). Manually led torch cannot turn profit this fact. More to the contrary, real weld mostly made in PB position has opposite no efficient unequal legs due to running a weld pool down, convex reinforcement and often root lack of penetration.

\subsubsection{Fillet weld noise factors}

A major problem with fillet welds is ensuring the gap between the components is within defined limits. Common sources of variability in fillet welding process include variations in part fit-up (root gap) and variation of the location of parts in the fixture (offset). These noise-factors have a great influence on real depth of penetration and thus weld size.

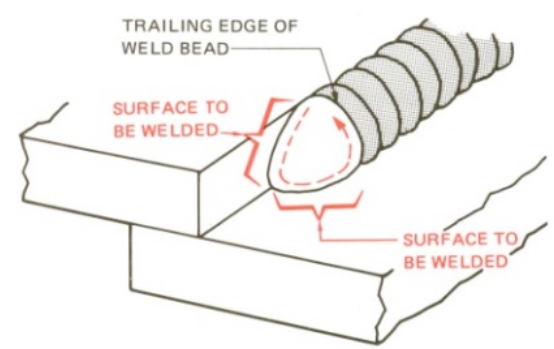

Fig. 3. Manual manner of fillet deposition [1]

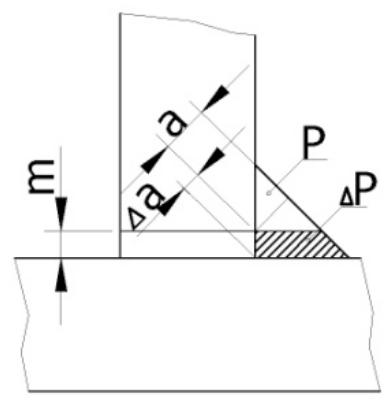

Fig. 4. Poor fit-up and wasted deposited area

Mostly a gap is not variable as codes assume but noise factor that represents sum of production and fit-up allowances and cannot be set. For fillet-deposited weld that grips two Tjoined sheets every gap between them affects waste of welddeposited area. Along the length of a T-joint, perfect fit is never possible, and some small gaps will exist. As illustrated on fig. 4 , if the size of the gap between the two members increases, and if the fillet weld leg size is kept the same, the actual weld throat and its load capacity decreases. In poor fitup fillet weld wasted area $\boldsymbol{\Delta P}$ dramatically increases with growing gap dimension $\boldsymbol{m}$ as showed on fig. 4 and following equation (4):

$$
\Delta P=m \cdot(\sqrt{2} \cdot a+m / 2)\left[\mathrm{mm}^{2}\right]
$$

E.g. weld sized $5 \mathrm{~mm}$ consume by $64 \%$ more material when $2 \mathrm{~mm}$ gap should be included. 


\subsubsection{Automatic and robotic fillet shape design and measuring}

Essentially automatic welding process proposal must differ from manual. First of all string bead root penetration has to be directed to the gap (fig. 5) and special high power density regime has to be used. This regime was revealed during our experimenting with new inverter source [4]. Our experiments with GMAW confirmed existence and usability of deep penetrated arc process that researched Mendez at all for GTAW (Gas-Tungsten-Arc-Welding) [5].

Measuring and optimization of fillet-penetrated weld supposes to choose some base factor to compare. Maximal reachable penetration with acceptable reinforcement for given source-wire-gas condition, as a result of DOE based experimental research, was proposed as the base value and signed as Fillet Efficiency [4].

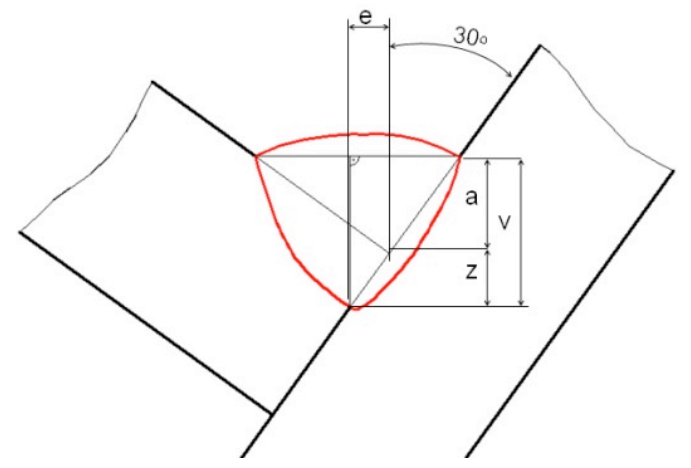

Fig. 5. Unequal-legged weld (deposit) with equal penetration

A value of max. weld penetration is the distance from the root of the fillet to the point at which fusion penetrates into the gap direction ( $\mathbf{x}$ on fig. 12). This unequal-legged outer weld shape was legalized in latest edition of standard specifications [9], that enable to count penetration of fillet weld towards the effective throat size and this shape in etched weld cross-section should to be close to ideal isosceles triangle with its vertex on fillet joint gap (fig. 6). This was challenge for measurement producers enable to measure these unequal-legged welds [6], fig. 7.

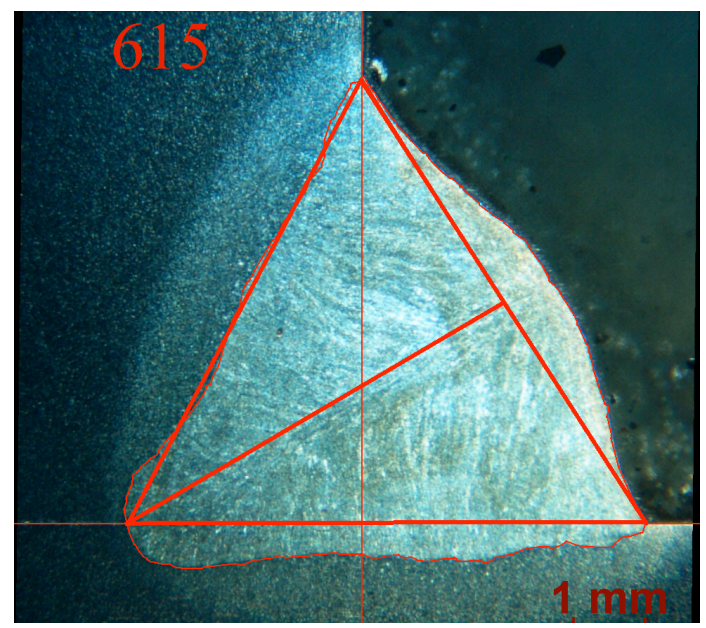

Fig. 6. Efficient shape of fillet-penetrated weld

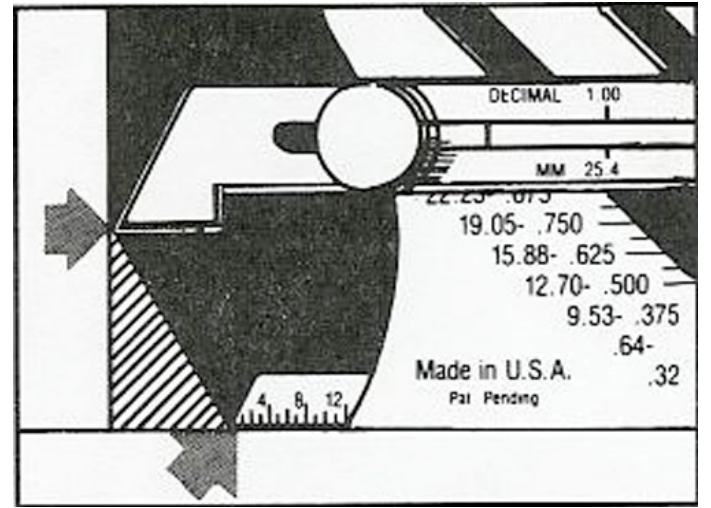

Fig. 7. Unequal-legged fillet gage [6]

\subsection{Mathematical models of Fillet Efficiency (FE) evaluation}

Two factors are principal for fillet efficiency evaluation depth of penetration $(\mathrm{x}, \mathrm{z})$ and outer fillet deposited shape and area $(\mathbf{P})$. Base of solved problem was to derive shape of ideal weld and evaluate rate of real and ideal shaped fillet weld. Three models were proposed and experienced during our several years' research:

$$
\begin{array}{lll}
\text { 1. } & P=f(z), & v_{t}=\text { const. } \\
\text { 2. } & P=f(x), & v=\text { const. } \\
\text { 3. } & v_{t}=f(x), & P=\text { const. }
\end{array}
$$

where $v, v_{t}, \mathrm{z}$ is described on Fig. 10.

\subsubsection{Model of penetration tailored weld geome- try}

The first model seems to be the most comprehensive. It introduces ideal welds shape compare that can be called as "depth of penetration tailored fillet weld geometry design". Weld deposited cross-section area $\mathbf{P}$, for constant (ideal) throat size $\mathbf{v}_{\mathbf{t}}$, is depended on reached depth of penetration $\mathbf{z}$. Schema on fig. 8 and diagram on fig. 9 show that a curve of this relation starts with full-fillet weld with no penetration and ends with full-penetration joint without added consumable.

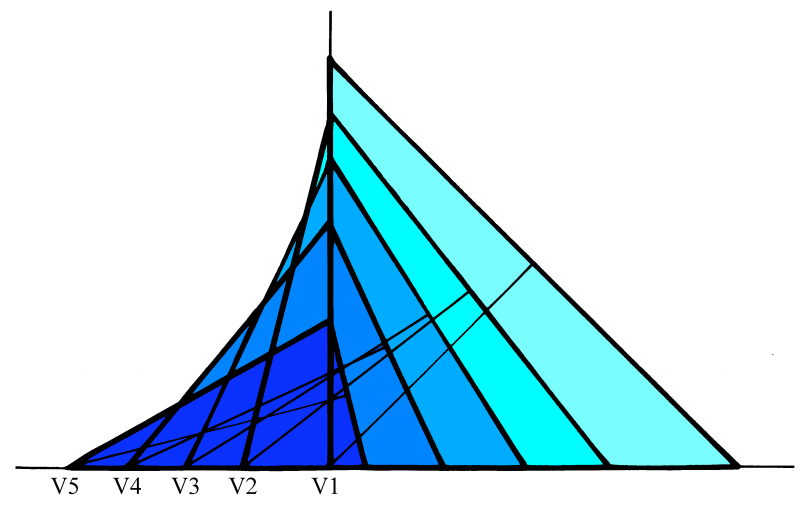

Fig. 8. Fillet deposited area $\mathbf{P}$ as a function of penetration $\mathbf{z}$ with constant throat size $\mathbf{v}_{\mathbf{t}}$ 


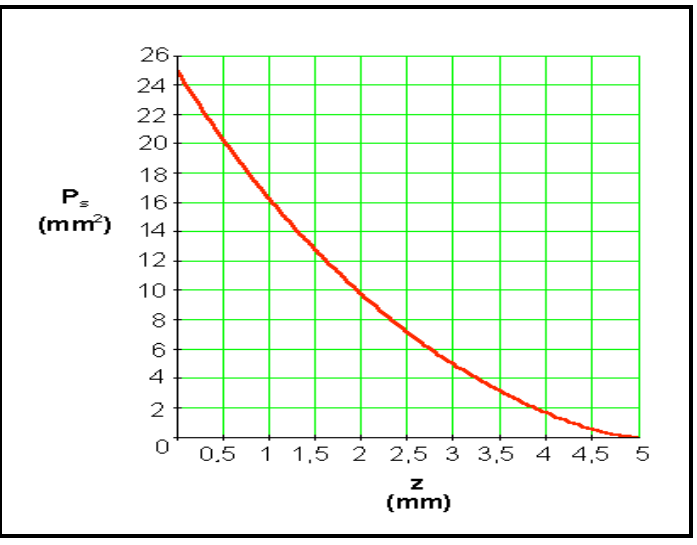

Fig. 9. Diagram $P=f(z)$ for $v_{t}=$ const. $=5 \mathrm{~mm}$

Max. value of Penetration Efficiency:

$$
\mathbf{P E}=\mathbf{z} / \mathbf{v}_{\mathbf{t}}
$$

of DOE optimized set of experiments there is characteristic value of every source-wire-gas system that intend variables field, deposition area and filet size included, where should be defined system effectively used. But this value is growing with amperage and travel speed growing, out of acceptable real fillet weld shape.

Real shape is concerned comparing of real fillet throat $\mathbf{v}$ to ideal $\mathbf{v}_{\mathbf{t}}$, derived from ideal shape of deposited weld of the same, constant value of deposited area $\mathbf{P}$.

\section{Deposition Efficiency:}

$$
\mathbf{D E}=\mathbf{v} / \mathbf{v}_{\mathbf{t}}
$$

is correcting factor of $\mathbf{P E}$ that evaluates waste of reinforcement and a weld pool running down of real weld and therefore it is a factor of quality assurance. Considering that $\mathbf{v} / \mathbf{v}_{\mathbf{t}}$ ratio allows higher reinforcement, for the 1-st quality welds achieving can be used more restricted:

$$
\mathbf{D E}=\mathbf{a} / \mathbf{a}_{\mathbf{t}} .
$$

\section{Fillet Efficiency:}

$$
\text { FE }=\text { PE . DE }
$$

considers both these factors and was chosen as response value for source-wire-gas system optimization.

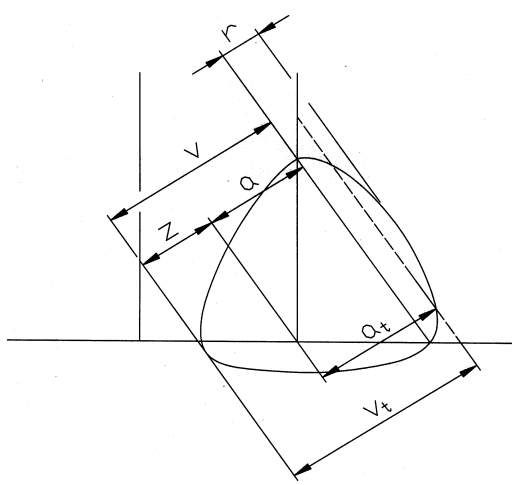

Fig. 10. Measured and calculated values

This model should be perfectly used for ideal or near ideal shaped and penetrated welds (fig. 6). Far from ideal shape, experiments are less valuable (fig. 11).

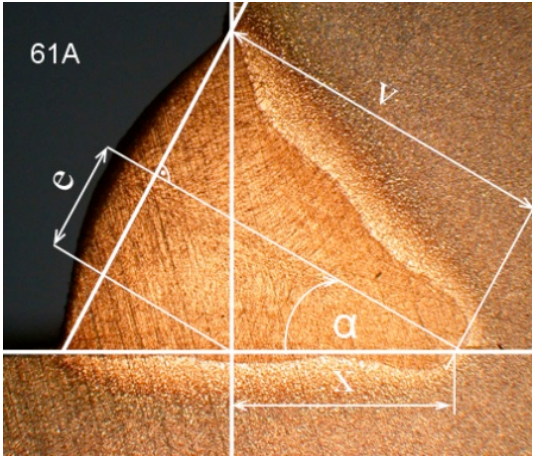

Fig. 11a

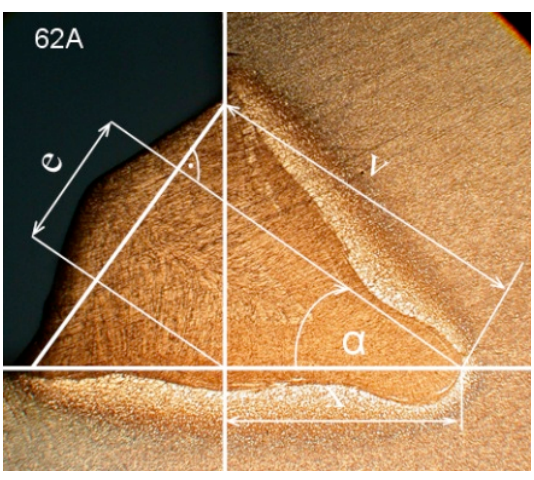

Fig. 11b

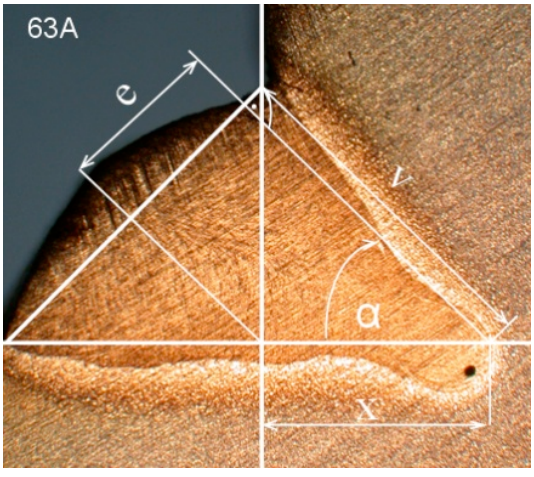

Fig. 11c

Fig. 11a,b,c. The same regime but different weld deposition shapes and different $\mathrm{DE}$ that evaluates waste of material

\subsubsection{Overwelding measuring model}

Second model was based on real fixed value of $\mathrm{x}$-axis penetration $\mathbf{x}$ (replacing the changing value of weld-axis penetration $\mathbf{z}$ in 1-st model) but for constant value of real throat $\mathbf{v}$, that is transforming to ideal shaped area $\mathbf{P}_{\mathbf{m}}$ (min. area for given throat).

Penetration Efficiency $P E=x / v$

is also corrected with

Deposition Efficiency $\quad D E=P_{m} / P$

when compared real and ideal value of $\mathbf{P}$ for resulted

Fillet Efficiency FE (10). 


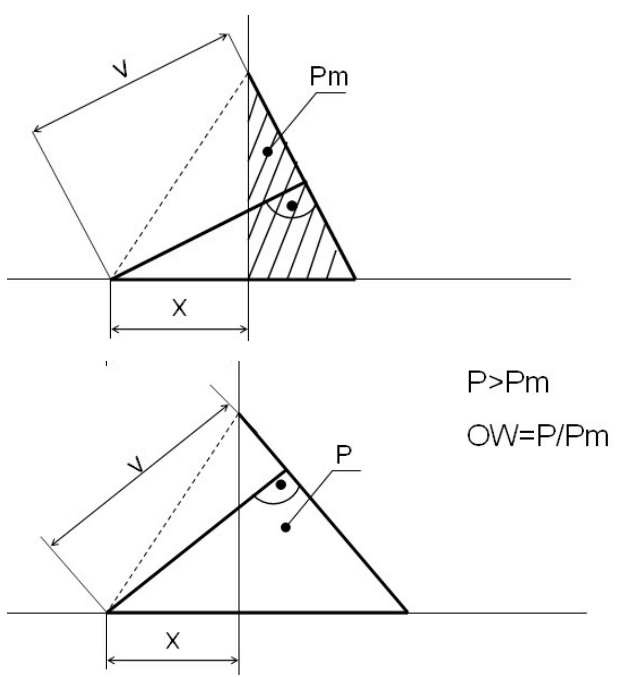

Fig. 12. Ideal and real weld with the same load-bearing throat

Real values - penetration $\mathbf{x}$ and throat $\mathbf{v}$ gives only one minimal triangle of deposition with area $\mathbf{P}_{\mathbf{m}}$. Proposed methodology issues from fact that real and ideal fillet weld have the same depth of penetration and effective throat and differ only with cross-sectional area of deposited (filled) material. Simple dilution of area values $\mathbf{P} / \mathbf{P}_{\mathbf{m}}$ gives Fillet-Penetrated Overwelding value at \% (fig. 12) that is inverse value of DE. This is the first attempt to express overwelding factor for deep penetrated fillet weld. This model can be used for good compare of deposition efficiency of any fillet weld shape.

\subsubsection{Technological model of equal deposition}

Third model is more close to real condition of GMAW process as mentioned above; penetration is matched to weld deposition because both are derived from amperage. Smaller deposition area cannot give the same penetration. Therefore $\mathbf{x}$ and $\mathbf{P}$ must be constant and $\mathbf{v}$ is changing (fig. 13) due to weld and torch geometry condition. Assumptions are similar to 1-st and 2-nd model.

\section{Penetration Efficiency $\quad P E=x / \mathbf{v}_{t}$,}

DE (9), but now efficiency of real weld of any shape should be directly compared with ideal shaped weld of the same penetration $\mathbf{x}$ and weld deposition area $\mathbf{P}$. This model with the most complex mathematical solution (quartic equation) seems to be the most practical solution of fillet-penetrated performance efficiency measuring and calculating.

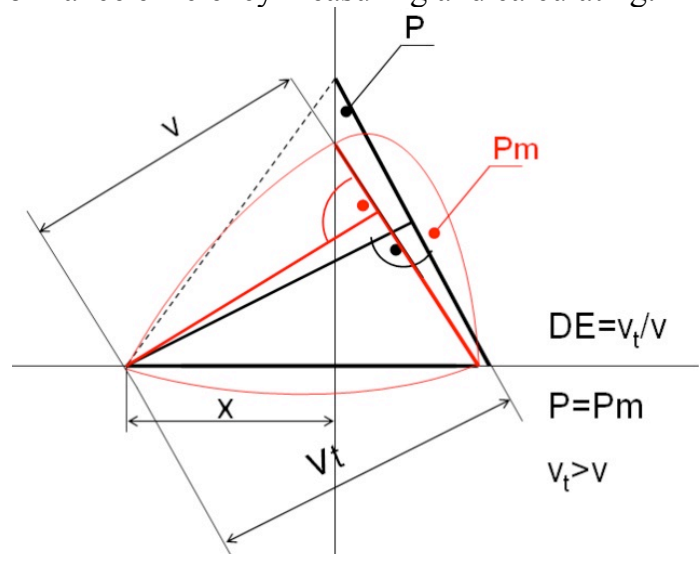

Fig. 13. Ultimate solution of FE measuring and calculating

\section{Power density GMAW performance and its optimization}

\subsection{Short-spray process}

In preliminary research all commonly used GMAW metal transfer regions were investigated (short arc, spray, rapid arc, pulsed arc) in synergic and out of synergy regimes, and all mentioned power density criteria were measured in addition to other geometrical parameters of an etched weld crosssection with the help of NIS-Elements software. The most interesting parametric field was found circa $6 \mathrm{~V}$ below standard spray process (fig.14). This field, throughout synergic lines, showed very deep penetration with high wire feed and travel speeds. Spray transfer was shortened and frequency of droplets was increased. An only excellent dynamic property of the used inverter power source enables this process. Several source-wire-gas systems were investigated and comprehensive diagrams of effective variables fields were obtained and published.

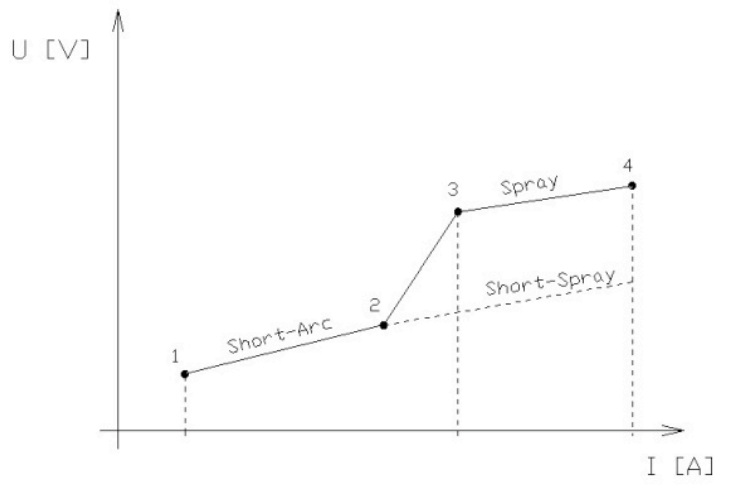

Fig. 14. Short-spray process in synergic diagram

Monitor record on fig. 15 shows rapid shorting (even more than 600 per second) of small droplets.

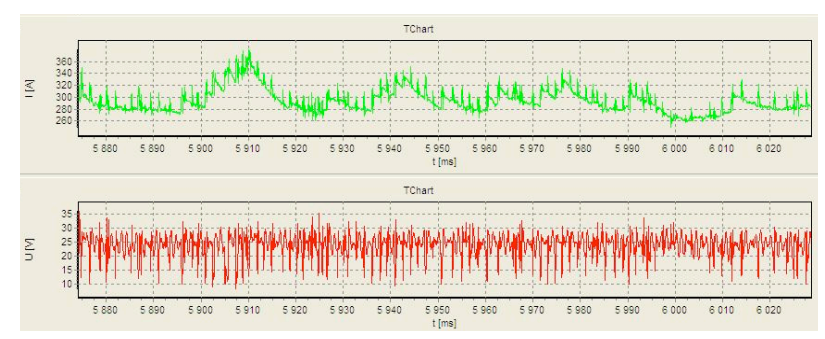

Fig.15. Short-spray process monitoring

\subsection{Automatic fillet weld noise factors}

The parts to be joined by fillet welds shall be brought into as close contact as practicable (AWS D1.1:2008). Special series of experiments were performed to study the effect of these noise factors on the fillet efficiency. The result seems to be quite promising to practical application because it was confirmed that root gap up to $0.5 \mathrm{~mm}$ has no or even beneficial influence to fillet efficiency (fig. 16) and also offset ranges $+-0.2-0.3 \mathrm{~mm}$ from the weld axis, depending on type of wire-gas composition, has also minimal influence on fillet efficiency. 


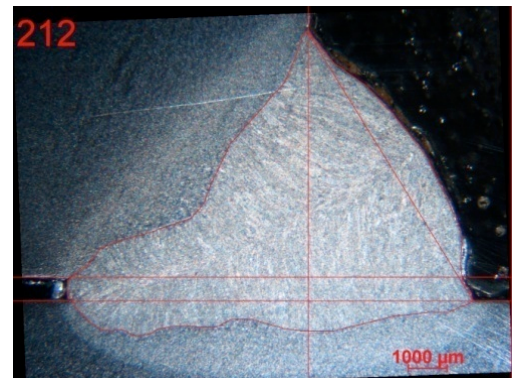

Fig. 16. Positive effect of small gap to penetration

\subsection{Variables selection and optimization}

Careful choice of variables is the basic necessity for successful results. Wire feed speed, travel speed, open arc voltage and contact tip-to-work distance are the main variables that can be set before welding. Amperage and voltage can be measured only during welding.

Our preliminary wide experimental research reduced all welding variables to 2 basic independent parameters - wire feed speed (WFS) $\mathbf{v}_{\mathbf{D}}$ and travel speed (TS) $\mathbf{v}_{\mathbf{S}}$. In respect to the defined goal, all remaining variables can be adjusted in a close dependence to these two main. Above mentioned research over an extensive parameters field allocated region of interest of near-optimum response conditions for given set of input conditions. Due to expected strong curvature in this region of FE response surface, statistical second order model "central composite design of experiments" was used - fig. 17 [7]. Choice of this model supposes a good knowledge of the process because the first step there is estimation of center (optimal) point and parameters levels range. Only solution, where point of maximum response is inside of field, is acceptable. Including minimum 3 center runs, design matrix consists of 11 sets of coded variables for experimental runs (tab. 1). For the case of two independent variables and their interactions the model is as follows:

$$
\mathrm{y}=\mathrm{b}_{0}+\mathrm{b}_{1} \mathrm{x}_{1}+\mathrm{b}_{2} \mathrm{x}_{2}+\mathrm{b}_{11} \mathrm{x}_{1}^{2}+\mathrm{b}_{22} \mathrm{x}_{2}^{2}+\mathrm{b}_{12} \mathrm{x}_{1} \mathrm{x}_{2}+\varepsilon
$$

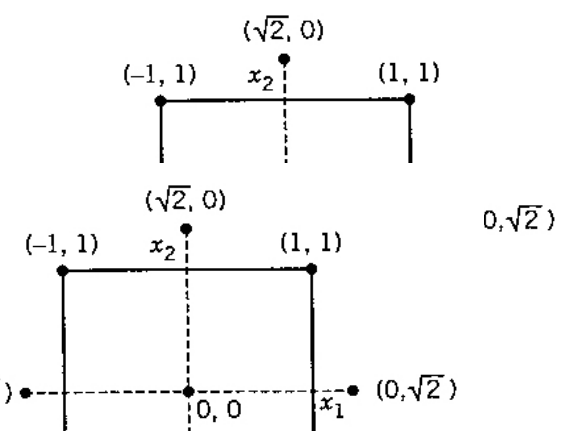

Fig. 17. Central composite 2 variables design

Table 1. Setting range of variables

\begin{tabular}{|c|c|c|c|c|c|}
\hline var./level & $-\sqrt{ } 2$ & -1 & 0 & 1 & $\sqrt{ } 2$ \\
\hline \hline $\mathbf{V}_{\mathbf{D}}(\mathbf{m} / \mathbf{m i n})$. & 11,6 & 12,3 & 13 & 13,7 & 14,4 \\
\hline \hline $\mathbf{P}_{\mathbf{M}}\left(\mathbf{m m}^{\mathbf{2}}\right)$ & 10 & 13 & 16 & 19 & 22 \\
\hline
\end{tabular}

Together with additional runs for stabilization and confirmation of FE response surface field, about 20 runs were performed for optimization of one set of input (material-sourcewire-gas) conditions. Resulted two-dimensional contours plots of optimal variables operational windows on the base of $\mathrm{v}_{\mathrm{D}}-\mathrm{v}_{\mathrm{S}}$ diagrams are shown in the next section. Number of experiments depends on a good estimation and is controlled with resulted statistical values.

\subsection{Quality assurance during optimization}

Several source-wire-gas systems were optimized as a foundation of potential database for implementation to robot control systems. Using $1.2 \mathrm{~mm}$ solid or cored wire, there was no case of optimized weld with non-acceptable outer shape according valid codes. The same can be said for $1.0 \mathrm{~mm}$ wire but without respect to quality level. The wire $0.8 \mathrm{~mm}$ was very difficult to optimize. Using high power density process for this diameter, narrow and reinforced welds were produced.

Except of outer weld shape requirements, no other defects were necessary followed. Small root pores were RTG evaluated as negligible and only very high power regime combined with "cold" gas mixture, improper weld geometry or great gap, effected hot crack (fig. 18) or tunnel porosity emergence.

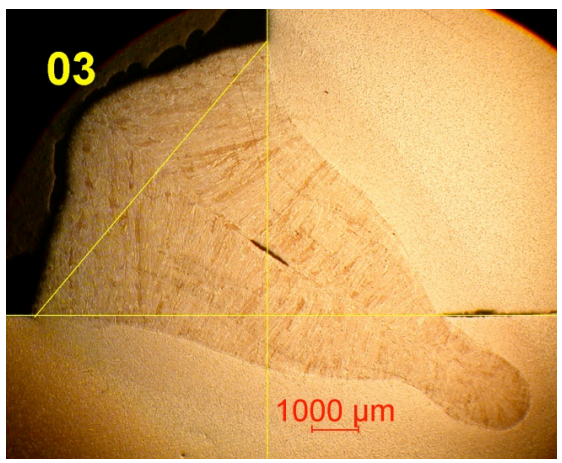

Fig. 18. Regime 448 A with $\mathrm{Ar} 92 \% / \mathrm{CO}_{2} 8 \%$ gas

Praxis realization of deep penetrated and unequal-filletouter-shaped welding needs employment of different quality assurance method. Precise solution would be with application of Laser scan as a measuring device for weld deposit geometry. Although every code permits to count penetration in computing the weld throat thickness, nobody in industry would realize it without attesting of real weld shape and depth of penetration. Contribution of penetration to fillet size should be measured only with non-destructive testing. Latest research of Noncontact Ultrasound "time of flight" weld penetration depth measuring [10] should be very promising for this purpose. Using RGLS TOF technique has proven to be accurate, precise and repeatable both off-line after welding and on-line during welding that enable closed loop control of weld penetration depth, analogical to other technological processes and can be incorporated into a robotic welding machine. Using closed loop control of weld penetration is associated with further lowering costs and improving quality. 


\section{Examples of source-wire-gas systems optimization (the same material)}

\subsection{System MIGATRONIC BDH 550 - ESAB Aris- torod $1.2 \mathrm{~mm}$ - AirProducts Feromaxx Plus $\left(\mathrm{Ar} / \mathrm{He} / \mathrm{CO}_{2}\right)$}

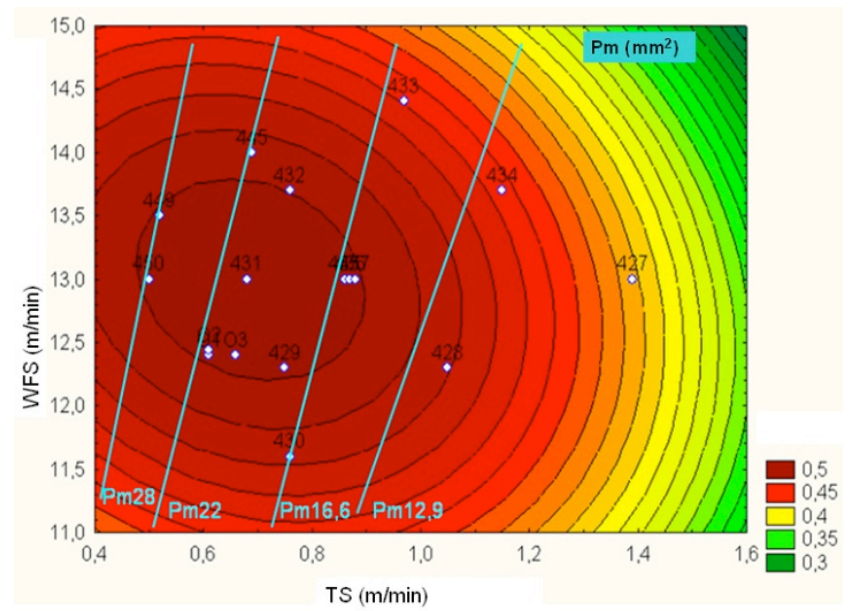

Fig. 19. FE optimized field

Fig. 19 shows the resulted diagram of system optimization, where there is evident optimal operational window of the main variables - wire feed speed and travel speed.

Near optimal weld no. 431 is on fig. 20.

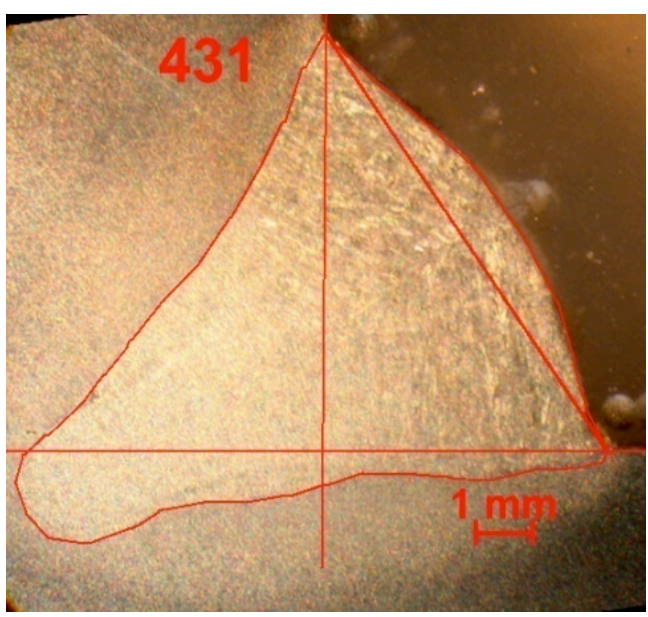

Fig. 20. The nearest weld to optimal peak

Due to He content in shielding gas mixture, efficiency of heat transfer is high that causes deep and regular penetration, without finger tip effect and gives more acceptable weld shape.

\subsection{System MIGATRONIC BDH 550 - Filarc PZ $61021.2 \mathrm{~mm}$ - $\mathrm{Ar} / \mathrm{CO}_{2} 82 / 18$}

Metal cored wire Filarc PZ 6102 has a higher deposition rate and wider and shallower penetration. Smoother surface with minimal reinforcement classify these welds as the best and of easier assured quality, but efficiency and productivity does not reach values of solid wires (figs. 21, 22).

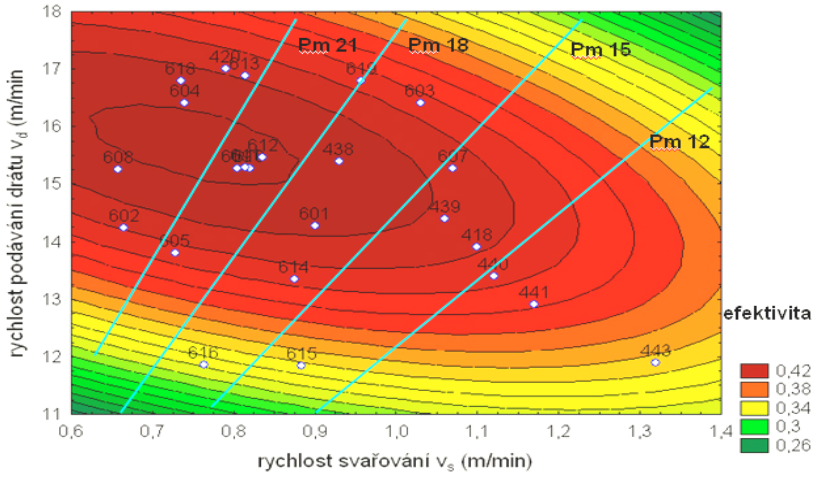

Fig. 21. FE optimized field

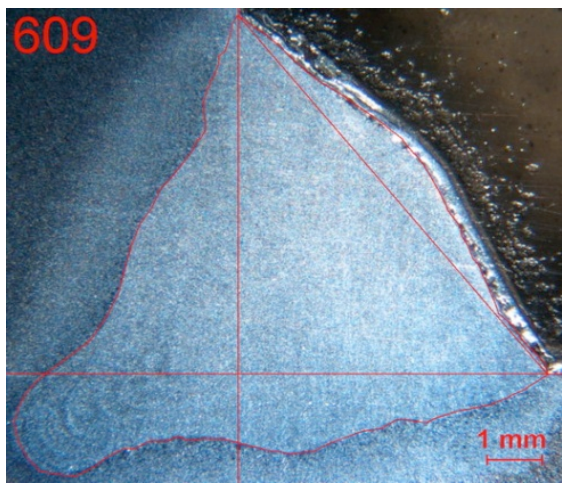

Fig. 22. The nearest weld to optimal peak

\subsection{System MIGATRONIC SIGMA 500 - ESAB Aristorod $1.2 \mathrm{~mm}$ - AirProducts Feromaxx Plus $\left(\mathrm{Ar} / \mathrm{He} / \mathrm{CO}_{2}\right)$}

The same wire and gas as in first case was combined with new inverter source. After a few preliminary experiments that showed excellent stability of metal transfer, experimental field was moved to higher parameters field, but it turned out too optimistic and until second set of experiments (fig. 23) showed regular enclosed and statistically stable optimized field (fig. 24), evidently moved to higher travel speed.

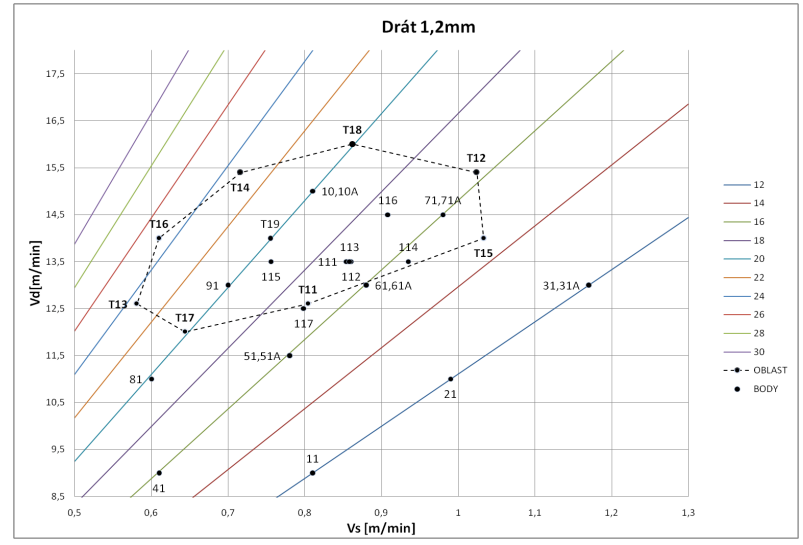

Fig. 23. DOE proposal with preliminary welds 


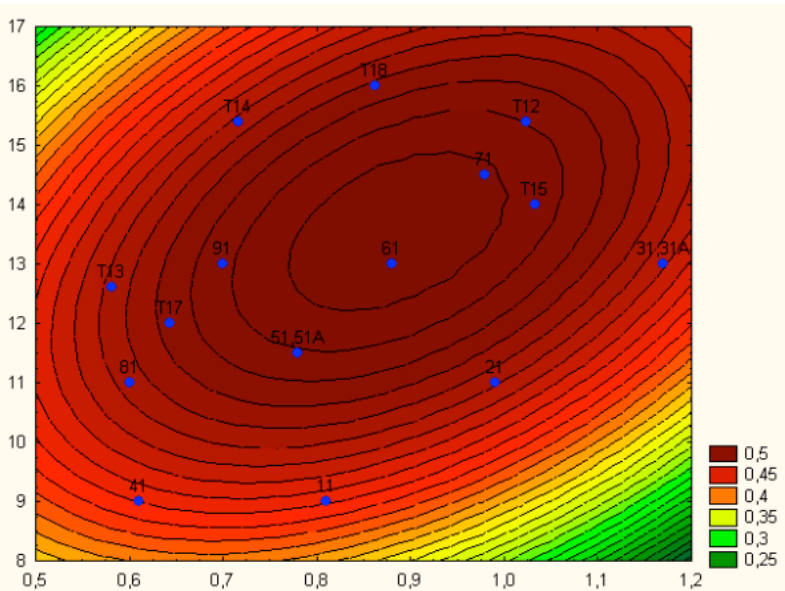

Fig. 24. Resulted FE optimized field

\section{V-grooved Butt weld design and per- formance optimization}

\subsection{Present state of design and performance (manual manner, overwelding)}

Poor fit-up for beveled weld (an excessive gap between the matching faces of the materials) is the most common imperfection caused with poor workshop practice or poor dimensioning and tolerance dimensions on drawings.

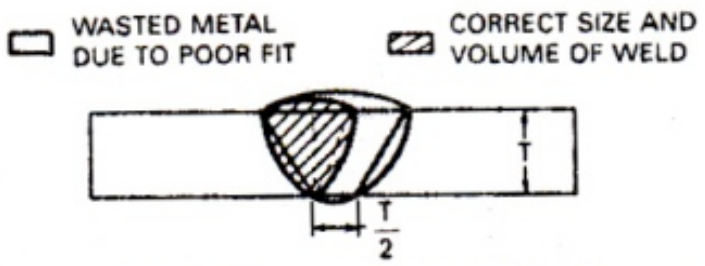

Fig. 25. Overwelding due to increased root opening of the groove [8]

In butt weld, cross section of wasted area $=$ thickness of material $x$ excessive width of gap as showed on fig. 25 .

To the contrary of a fillet weld, butt weld is always designed as full-penetrated and in case of one side weld without backing (e.g. tube) for manually performed welding, that is showed on fig. 26, and minimum gap is prescribed for assurance of a perfect fusion of root back side. Welding to open root would be performed slowly with low parameters and therefore low penetration and productivity. Only experienced welders can provide this work out of position in RTG quality.

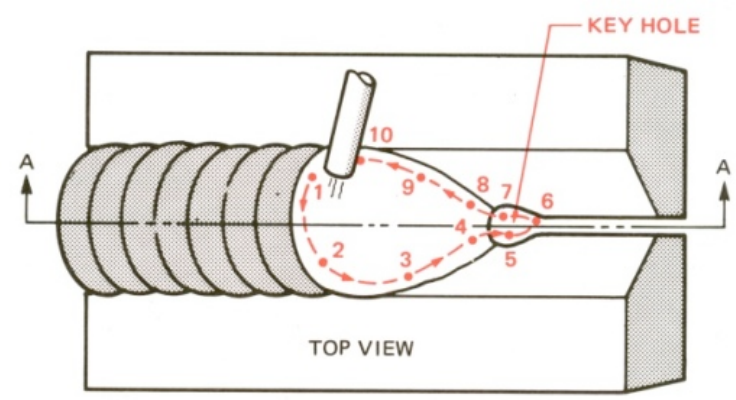

Fig. 26. Manual manner of butt weld deposition with back side root fusion assurance [1]

Root ceramic backing and if possible double-sided welding may replace this difficult, slow, quality-risk and wasteful method, but automation is really the only efficient solution.

\subsection{Automated butt weld design shape and pene- tration}

Automated string bead high power density weld has deep and uniform penetration and dilution. The shape of the groove should be tailored according to its experienced optimized shape. Great difference between design for manual and automated V-grooved weld is shown on fig. 27 [8]. Doublesided welding, when possible, needs half of the deposited area and ensures better root penetration (fig. 28) as it is known from literature [8].
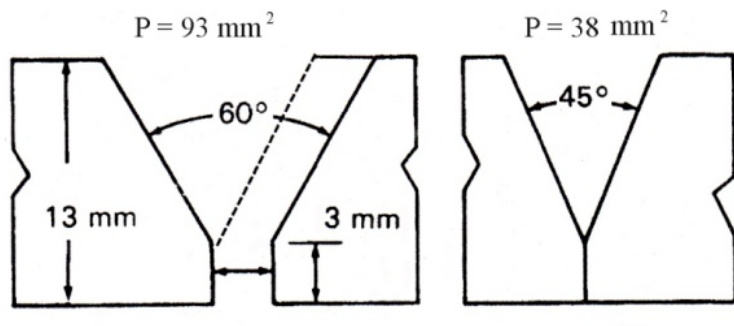

$3 \mathrm{~mm}$

Fig. 27. Bevel design for manual and automated welding

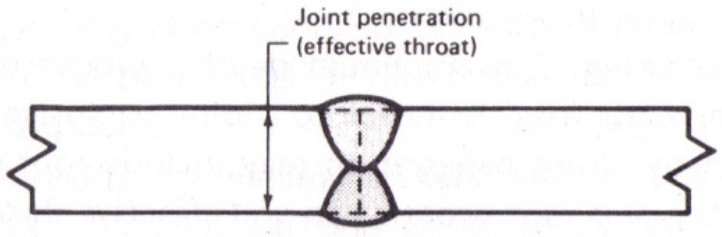

Fig. 28. Double-sided welding

\subsection{Mathematical model of V-grooved weld shape efficiency}

The objective of an efficient V-grooved weld is the same as in fillet weld - to reach maximal rate of penetration with minimal deposition, but now deposited part is defined by the $\mathrm{V}$-groove area that is determined by the groove depth $\mathbf{a}$ and the groove angel $\boldsymbol{\alpha}$ on fig. 28. Deposited area can be calculated with (15):

$$
P=\sqrt{a^{2} / \sin \alpha}
$$

Compared to the fillet weld, mathematical model of the Vgroove is very simple:

$$
\mathrm{BE}=\mathrm{v} / \mathrm{P}
$$

Butt Efficiency $\mathbf{B E}=$ maximum rate of load-bearing dimension $\mathbf{v}$ for definite deposited area $\mathbf{P}$.

Efficiency for butt weld with reinforcement is:

$$
\mathrm{BE}=\mathrm{v} / \mathrm{P}_{\mathrm{n}},
$$

where $P_{n}$ is area of real weld deposition with reinforcement. 


\subsection{V-grooved weld shape efficiency optimiza- tion}

DOE optimization of $\mathrm{V}$-grooved welds has one parameter more than for fillet welds and minimal 3 variables field should be estimated for experimental program of designprocess optimization. Fig. 29 shows preliminary DOE rough proposal for 2 dimensions of $\mathrm{V}$-groove design optimization for deposition area, experienced in fillet weld research and with welding parameters, attested in fillet research. Results showed susceptibility to hot cracking and worse penetration accuracy for narrow bevels.

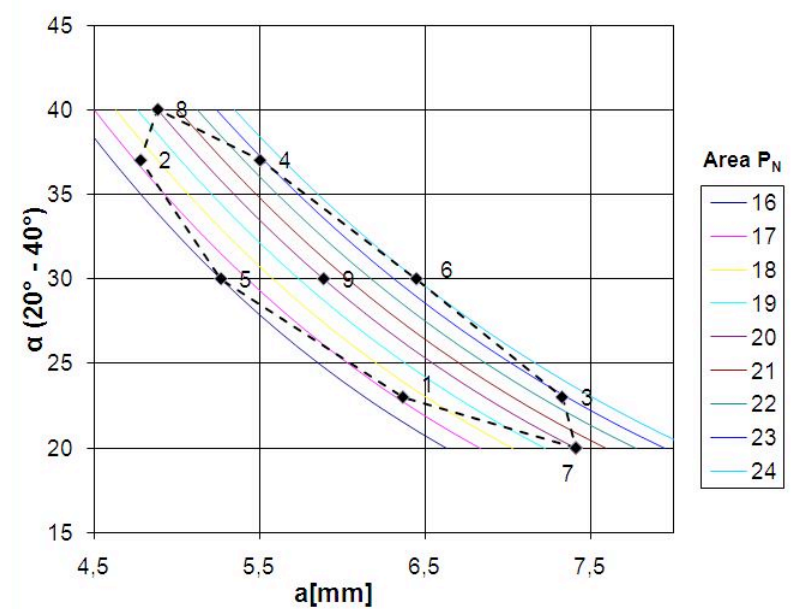

Fig. 29. DOE bevel edge proposal

With respect of these results, following 3 parameters DOE proposal used bevels range moved to higher values, out of hot cracks field, using resulted process parameters field from fillet weld optimization. Tunnel porosity for higher travel speeds showed as another quality risk in this case, on the contrary to fillet welds.

Fig. 30 shows an example of deep penetrated V-grooved weld, evaluated with geometric analysis, with a help of SW NIS-Elements.

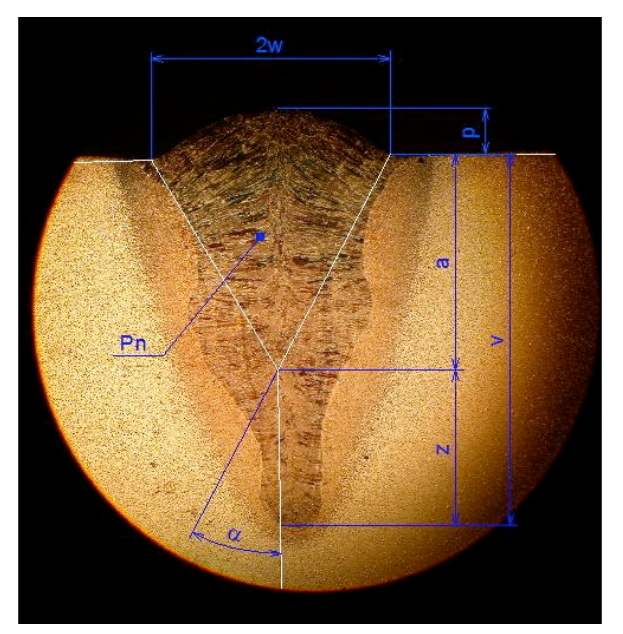

Fig. 30. Geometric analysis of V-grooved weld

\section{Conclusions}

Substantial differences in the technological characteristics and conditions between manual (semiautomatic) and automatic GMAW processes were discussed and original approach to the optimization of GMAW automatic process was proposed and demonstrated. GMAW process as the most employed and enhanced welding technology has a great variety in systems and conditions used. In a majority of cases, optimization of a particular application is still realized with trial-and-error approach that spends a lot of time and costs. Proposed method requires material and time for only about 20 to 30 weld designs, so the tests performance and evaluation could minimize costs and redundant procedure development and can save industry a lot of money. Several sourcewire-gas systems were optimized as the start of potential database building for needs of designers and technologists as one of presented essential conditions for the especially real fillet throat size control welding process application.

Moreover a new parametric field of stable metal transfer was discovered that markedly improves penetration and therefore performance efficiency and brings no additional investments and is more versatile than new Hybrid Laser-MIG process that is solving the same problem.

\section{Acknowledgement}

Special thanks to MIGATRONIC CZ for technical support. This study is included in the frame of the research plan MSM 4674788501 .

\section{References}

1. L. Jeffus, H.V. Johnson, Welding: Principles and Applications, 2nd ed, Delmar Pub., (1988)

2. J.N. DuPont, A.J. Marder, Thermal Efficiency of Arc Welding Processes, Welding Journal, 406 - 416, (1995).

3. A.A. Wells, Heat Flow in Welding, Welding Journal 31(5), (1952)

4. Z. Hudec, GMA Fillet Welds Design and Process Parameters Optimization, Ph.D. thesis, Technical University of Liberec, (2005)

5. P.F. Mendez, T.W. Eagar, Penetration and Defect Formation in High- Current Arc Welding, Welding Journal 82(10), 296 - 306 (2003).

6. G.A.L. gage co. catalogue

7. R.H. Myers, Response Surface Methodology, John Wiley \& Sons Inc. N.Y., (1995)

8. AWS Welding Handbook

9. EN ISO 5718

10. A. Kita, I.C. Ume, Measuring On-Line and Off-Line Noncontact Ultrasound Time of Flight Weld Penetration Depth, Welding Journal Jan., 9-17 (2007). 